\title{
Philosophy-based Analysis on Chinese Postgraduate Education Connotation
}

\author{
Meihong Chen ${ }^{1}$, Yongmei Hao ${ }^{1}$ \\ ${ }^{1}$ School of Physics and Optoelectronic Engineering, Nanjing University of Information Science and \\ Technology, Nanjing, 210044, China
}

Keywords: Postgraduate graduation; Philosophy; Connotative development; Thought; Teaching

\begin{abstract}
With the impact of swift and violent trend for popularization of higher education, whether we can keep or even enhance the teaching quality has become a problem demanding prompt solution for postgraduate graduation in our country at present. Faced with this problem, our country and the education department concerned shall not only fully support the higher learning institutions with respect to teaching hardware and faculty, but also consider guiding the track of postgraduate development of our country through pilot ideas so as to cultivate higher talents who have more social competitive power and more thoughts. Therefore, this paper tries to treat and analyze the connotative development and essence of postgraduate education of our country from the angle of view of philosophy and to experience the philosophical thinking needed for postgraduate education.
\end{abstract}

\section{Introduction}

The so-called connotative development of China's education, which is the result based on social and economical transformation of China and people's increasingly rising educational appeal, not only reveals the essence of postgraduate education but also tries to optimize the educational structure as the basic feature so as to play an active guiding and propelling role in the postgraduate education of China.

\section{Connotative development of postgraduate education}

"Problem is the slogan of time and it shows the most actual voice for one's mental state." This is one of Marx's philosophical sayings and it also cries out the inner voice of the development road of postgraduate education in our country and also reflects the demand of times. Indeed, the development track of postgraduate education reflects the objective appeal for social and economical transformation due to development of times, also reflects that the Chinese people's sight and field of view in educational problems are changing gradually, which is the intendment of connotative development of postgraduate education, the transformation of social system and people's thinking and the development road of exploration and self-seeking.

\section{Epochal character of connotative development}

China's postgraduate education is epoch-making, because it experienced the reform and opening-up period as well as the market economization. From the initial stage of reform with scanty talents to the new era with a galaxy of talents, the postgraduate education is really "born under the red flag and walking in sunshine”. Nowadays, with educational system reform and rapid transformation of social economy in this country, the development, reserve and utilization of high-end human resources has become a significant condition for the transformation development of society. It also indicates that the progress of a country needs talents and only the high-quality talents can make the development of the country to take a qualitative leap. As said by Marx, for the development of postgraduate education in China, only when you raise questions and cry out the inner voice of times, you can find the road forward; i.e. to provide high-quality talents for the transformation of economy and society of China, conform to the times and strategically conduct the connotative development for the postgraduate development. 


\section{Popularization of connotative development}

With the ceaseless improvement of national economy, a growing number of people desires for postgraduate education, the highest education in Chinese society, which raise a new ordeal for the development of postgraduate education. Unceasing increased enrollment of students and expansion of faculty in colleges and universities precisely illustrate the problem. On the one hand, the popularization of postgraduate education shows the increasing generalization in the society's demand for talents and requirement for quality of talents; on the other hand, it also shows the transformation in people's awareness for higher education in society. All these changes promote the postgraduate education to change in the direction of connotative development.

\section{Inevitability of connotative development}

From the historical origin and the point of view of strategy, the development of postgraduate development in our country has its inevitability. Since the reform and opening up for just 30 years, from the resumption of college entrance examination to the expansion of enrollment scale, the number of postgraduates has increased by nearly $70 \%$ and the number of subjects also has been increased from 13 to more than 140. Meanwhile, there are more and more types of professional degrees. All those data mean that our country has become a genuine power of postgraduate education. That is to say, since the reform and opening up, under the influence of the spreading of open overseas cultural thoughts, people's thinking has been gradually expanding and their living standards have been remarkably enhanced in our country. The country's growing development need in science and technology and all the other academic sectors promoted our country to put forward the educational strategic guideline of "developing the country through science and technology" at the end of the $20^{\text {th }}$ century. As the highest education of the country, postgraduate education, which is the forefront for talent transmission, should shoulder the heavy burden of developing the construction of modernization of the country. In a word, the connotative development of postgraduate development is inevitable due to the transformation of national thoughts and social development.

\section{Essence of connotative development of postgraduate education}

\section{Qualitative and quantitative changes}

Only when one understands and makes out the essence of connotative development of postgraduate education, one can clearly understand the problems which have been caught are emerging and may arise in the educational development and then one can clarify true development direction of postgraduate education.

On one side, the connotative development of postgraduate education shall focus on considering how to connecting the interior with the exterior, which reveals that one looks at a problem from the angle of materialism; i.e. the connection between the qualitative change and quantitative change in the connotative development of postgraduate education. Though it is said that the development of everything needs to go through quantitative change and qualitative change, both of which have no similarity in their features, as a matter of fact, they must interdependent with each other and influence each other. For the postgraduate education in our country, as of the beginning of reform and opening up, the postgraduate education must absorb more external forces to supplement and enrich itself through the extensional development trend because it was small in scale and weak in strength and everything was in the start-up phase. These are the external powers which promote the development of postgraduate education business, such as increase in the governmental investment, strengthening of research institutions, expansion of students and enriching of faculty. In this phase, any changes concerning postgraduate education are quantitative ones. A growing number of colleges and universities were established, set their own postgraduate schools and expanded their own research subjects and facilities. That is to say, the postgraduate education of our country was in the extensional development pattern of extremely strong expansion for a long time, which was a type of enrichment in forms and accumulation in quantity. When the quantity develops to a certain extent, the speed of development may slow down gradually; then, the qualitative change happens quietly. This conforms to the basic law of social development. The connotative development of postgraduate education in 
our country is exactly a hope which is pursued by people, which is the change in the essence of hope. The connotative development of postgraduate education in our country insists on the "pattern of using the domestic demand and connotation of something as the main motivations and resource accumulation". Frankly speaking, it emphasizes the stabilization and harmony of structure, strengthening of inner factors, improvement of quality and enhancement of competitiveness. All these are attributive-based, internal and unpredictable for the educational development. If it is necessary to concretize such connotative development to a target, that will be the cultivation of the quality of students. At the same time, more breakthroughs are expected in the tutors' capacity, management level of educational and teaching organizations, arrangement of professional structures, layout of educational funds as well as the transportation of talents etc., which is the development process from quantitative change to qualitative change. The period must be very long. Being developed for nearly a hundred years, China's postgraduate education experienced abundant vicissitudes and reforms. However, the postgraduate education of our country reveals its powerful tension during the process of qualitative change and it is also the miniature of times reform, so to speak.

On the other side, the connotative development of postgraduate development truly shows its substantial difference with the extensional educational development in the old days and the difference is that such connotative development not only pays attention to the improvement of quality but also focus more on the optimization of structures and long-term benefits and can see far more than deeply than qualitative change. The connotative development of postgraduate education brings a lot benefits for the sustainable development of a school; such improvement of teaching quality and optimization of research system offer foresight and sagacity not only in the postgraduate education of our country but also the development of our country.

\section{Structure and quality}

For a school's postgraduate education system, the optimization of structure is precisely the optimal integration of tutor team. In many famous institutions of higher education, usually, the talents of different ages, with different experiences, at different levels, in different fields, in different environments and with different ideas get integrated; the highest state of the integration of such talents is the final unification to form a resultant force to help the postgraduate education system to make progress. From the professional viewpoint, such ratio of teachers and students who intends to become a resultant force and the classification pattern of talent cultivation can also give a full play to all the technological forces in the postgraduate education system and also cover the knowledge fields rather widely. The optimization mechanism will naturally enhance the internal teaching quality and external social evaluation, improve the expansion and forwardness of academic researches and provide more possibilities for the high-quality cultivation of postgraduate talents. Besides, in such optimized structural system, the academic atmosphere is more ideological and the academic idea is more advanced with the solid academic hardware and software configuration as the basis of innovation. Therefore, without any problem in itself, such structure-optimized pattern is tantamount to a type of virtuous circle and can be used for reference for the postgraduate education in the industry.

Quality improvement is the inevitable forerunner of structure optimization and they are interdependent. For the connotative development of postgraduate development, their common performances constitute the core essence of postgraduate education. If the optimization of structure is the guarantee for the development of postgraduate education system, the guarantee of quality is the greatest motivation for development.

\section{Due attitude and philosophy for postgraduate education}

\section{Rigorous scholarship}

In all ages, rigorous scholarship should be the excellent philosophy of Chinese traditional education; for the current postgraduate education, rigorous scholarship is still a prerequisite for cultivating elites and providing the society with high-level talents. As the postgraduate education 
belongs to the scholarship system combining "education and scientific research", it is characterized by educational frontier and will inevitably endure the academic evaluation and questioning by the social reality. The postgraduate education institute of each university shall regard the high-level talent cultivation and obedience to rigorous academic attitude as the historical mission given by the society and as the real rule for self-survival. Rigorous scholarship also reflects the attitude of life of a person or even a system. For postgraduates, rigorous scholarship means striving for achieving their personal goals; for tutors, rigorous scholarship means the most basic occupational ethics; for the university, rigorous scholarship means sustainable development. Therefore, rigorous scholarship gives different meanings to different individuals; but they have an intercommunity: eager for the true, the good and the beautiful as well as the view of life values of due diligence. That is to say, rigorous scholarship can reflect the truth in life and shall be abided by each scholar.

\section{Educational philosophy of highlighting personality}

Disrespect to students' personalities has been always existing in the education in our country, which is wrong and is still difficult to be corrected. As the educational pattern integrating scientific research and teaching, the postgraduate education shall avoid, by all means, suppressing students' personalities. It is required to insist on the flexible ideology and open teaching personality during teaching practice. Since the early 1980s, our country has introduced the lab concept from University of Berlin and brought the scientific research in teaching activities, which symbolized the qualitative change of postgraduate education; such pattern integrating scientific research and teaching infinitely magnifies the scientific creativity and openness in university education. So, scientific research and creation is an industry that vivifies thoughts and highlights personalities; thus, the postgraduate education centering on research shall also have such attitude.

\section{Academic ideology of advocating freedom}

Academic freedom and "teaching is learning" are academic thoughts based on postgraduate education. They indicate that the postgraduate education shall respect the academic freedom and democracy and adhere to the teaching relationship of teacher-student mutual improvement. Academic freedom is the lifeline of academic development. It emphasizes ideological freedom, inmost freedom and rationality-based judgment freedom. The three "freedoms" are especially important for most postgraduates and tutors who research the unknown science. Only by liberating the thinking and encouraging researchers' spirits of innovation and exploration can the postgraduates become brave in expressing their ideas, arguing, encouraging each other and demonstrating the team spirit during practical teaching and experiments, so as to find and create unexpected new things. However, the precondition of academic freedom is existence on the basis of seeking the truth; academic freedom shall also have principles and bottom line, so as to really achieve the equal and democratic cooperation relationship and teaching relationship.

\section{Academic spirit of serving the society}

Postgraduate education shall serve the society, and this is the essence. As mentioned above, both the system structure optimization and quality improvement of postgraduate education are to output more excellent talents and serve the mass society. Thus, as the highest-level education in our country, the postgraduate education is the educational system closest to the society and is closely linked to the social development. Postgraduates shall be able to withstand the evaluation and test by the society, and shall practically push the social development and change. Therefore, postgraduates shall be social service oriented during educational practices and activities, shall not only provide the society with scientific research achievements, but also strive for continuously meeting the needs of social development and output high-level talents, which is also the mission of postgraduate education system.

\section{Summary}

From the perspective of philosophy, the postgraduate education in our country has profound connotation. The educational thought of connotative development fits in with the management thought of striving for structural optimization, self-quality improvement, and system development 
and improvement involved in western social philosophy; abstract teaching philosophy conforms to the eastern Confucianism of "extensive learning, detailed consultation, deliberate thinking, clear identification and practical action". Therefore, from the perspective of philosophy, the postgraduate education in our country shall be of versatility and harmonization, and shall be the perfect combination between eastern restraining and rationality and western openness and sensibility.

\section{References}

[1] Chen Meihong. Analysis on Reform Thought of Postgraduate Teaching, China Adult Education, 2013

[2] Lv Xiangqian and Zha Zhengao. Philosophical Thinking on Connotative Development of Postgraduate Education in Our Country, Academic Degrees \& Graduate Education, 2014(4).

[3] Zhao Jun. Theory of Thought Categories of Postgraduate Education. Xidian University, 2004.

[4] Zhang Dan. Philosophical Concepts Due for Postgraduate Teaching. Inner Mongolia Normal University, 2010.

[5] Chen Meihong. Thinking on Postgraduate Quality Training, China Education Innovation Heral, 2012

[6] Chen Meihong. Mastering the Philosophical Law for Physical Teaching, New Course Learning, 2010 